\title{
Soybean phospholipase D activity determination. A comparison of two methods.
}

\author{
By E. Tosi, G. Ballerini, and E. Ré
}

\begin{abstract}
Centro de Investigación y Desarrollo en Tecnología de Alimentos (CIDTA), Facultad Regional Rosario - Universidad Tecnológica Nacional, Zeballos 1341 Rosario - CP: S2000BQA - Argentina. Fax: (54) (341) 4484909; E-mail: tosienzo@ ciudad.com.ar
\end{abstract}

\section{RESUMEN}

Fosfolipasa D en soja. Comparación de la actividad determinada por dos métodos.

Se evaluaron dos métodos para determinar la actividad de la fosfolipasa $D$ en soja debido a que existe discrepancia entre los resultados publicados. Un método se basa en la extracción de la enzima de la harina resultante de la molienda del grano de soja entero, cuantificando la actividad sobre el extracto. En el otro método, la cuantificación se realiza sobre la harina del grano entero molido, sin extraer la enzima. En el método de extracción se optimizaron tanto el tiempo como el número de extracciones. Los mayores valores de actividad de la fosfolipasa $D$ se obtuvieron por el método sin extracción de la enzima. Este método es más simple, exige menos tiempo de ejecución y las condiciones del medio en que actúa la fosfolipasa $D$ se asemejan a las condiciones encontradas en la industria aceitera.

PALABRAS-CLAVE: Actividad de la fosfolipasa D - Fosfátidos hidratables - Fosfátidos no hidratables - Fosfolipasa D - Soja

\section{SUMMARY}

Soybean phospholipase D activity determination. A comparison of two methods.

Due to a discrepancy between previously published results, two methods to determine the soybean phospholipase $\mathrm{D}$ activity were evaluated. One method is based on the extraction of the enzyme from whole soybean flour, quantifying the enzyme activity on the extract. The other method quantifies the enzymatic activity on whole soybean flour without enzyme extraction. In the extraction-based-method, both the extraction time and the number of extractions were optimized. The highest phospholipase D activity values were obtained from the method without enzyme extraction. This method is less complex, requires less running-time and the conditions of the medium in which phospholipase $D$ acts resemble the conditions found in the oil industry.

KEY-WORDS: Hydratable phosphatides - Non hydratable phosphatides - Phospholipase D Phospholipase D activity - Soybean

\section{INTRODUCTION}

Crude soybean oil has a high content of organic phosphorus, most of it in the form of phosphatides soluble in oil. Those phosphatides might cause serious processing problems such as oil darkening during deodorizing and physical refinement, catalysts inhibition during hydrogenation and gum formation. To reduce phosphatide concentration, a degumming step is included in the oil processing. Most phosphatides in soybean oil are hydratable and can be easily and economically removed from the crude oil by aqueous degumming. Non hydratable phosphatides (NHP) can also be present and, if their concentration is high, the reduction of phosphorus concentration by aqueous degumming is difficult and their elimination requires complex and expensive treatments with acid and/or alkali.

The amount of NHP in the crude oil is significantly increased when the phosphatidylcholine, a hydratable phosphatide, with higher concentration in soybeans, is changed into phosphatidic acid (a NHP) by the catalytic action of phospholipase D (PLD) (Eq. 1).

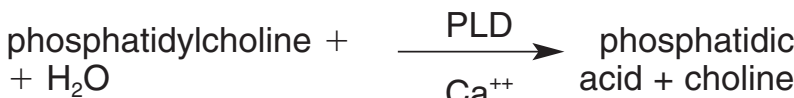
$\mathrm{Ca}^{++}$acid + choline

NHP occurrence depends on several factors such as soybean variety and quality, weather conditions during growing and harvesting, and the action of the soybean-native enzymes during storage and industrial processing. The key to avoiding NHP formation, is to inhibit these enzymes, especially the PLD, in the stages previous to the oil extraction process.

Discrepancies in the values of PLD activity (PLDA) arise from comparing the results obtained by List et al. $(1990,1992)$ and by Tosi et al. (1999). The PLDA found by Tosi et al. was 150 times the PLDA found by List et al. In their works, List et al. (1990, 1992) applied the method of extracting the enzyme from the soybean original matrix according to a modification of the method proposed by Nakayama et al. (1981) to extract the PLD from white cabbage.

The extracted PLD was then mixed with soybean lecithin as substrate. On the other hand, Tosi et al. (1999) used a method based on the action of the PLD, contained in the soybean original matrix, by mixing up milled soybean with soybean lecithin as substrate. Both authors used the same 
method (Bergmeyer and Gavehn, 1974) to quantify the total released choline, which allows the PLDA quantification.

The reason for the above mentioned variability may be related to the extraction process variables, such as extraction time and number of extraction steps. No methodological details about the PLD extraction were included in List et al. works (1990 and 1992) thus, an explanation of such differences in the results was impossible to find. Even factors such as enzyme inhibition due to its interaction with the extraction medium may be responsible for PLDA decrease, but such effects are out of the scope of the present work.

Due to the importance of PLD action in soybean oil production, the aim of this work is to optimize the PLD extraction method from milled soybean by determining the optimum extraction time and the number of successive extractions. Subsequently, a comparison was performed between PLDA values measured by the optimized extraction method and by the method without extraction.

\section{MATERIALS AND METHODS}

\subsection{Materials}

Physiologically mature, not thermally treated, good quality soybeans, and with about $13.5 \%$ (wet basis) moisture content were kept at about $25^{\circ} \mathrm{C}$ in tightly closed jars until use. Soybean lecithin and ammonium tetrathiocyanodiammonochromate (ammonium reineckate) were from Sigma Chemical Company (St. Louis, MO, U.S.A.). Other chemicals used were from Merck (Darmstadt, Germany). All reagents were ACS reagent grade.

\subsection{Phospholipase $D$ activity determination}

Briefly, PLDA determination was based on the action of the phospholipase D, either extracted according to List et al. (1990,1992), or not extracted but remaining in the original soybean matrix according to Tosi et al. (1999), upon soybean lecithin releasing choline (Eq. 1). The amount of released choline in this reaction was determined by the method of Bergmeyer and Gavehn, (1974), the absorbance was measured at $520 \mathrm{~nm}$ by spectrophotometric methods.

\subsection{PLDA determined by the extraction method}

The phospholipase $D$ was extracted from milled soybeans (List et al. 1990,1992) by a modification of the method proposed by Nakayama et al. (1981). Methodological steps were established as follows:

1. Mill about $10 \mathrm{~g}$ of soybeans in a refrigerated mill up to ASTM \# 40 mesh.

2. Determine moisture content using about $4 \mathrm{~g}$ of milled soybean, according to ISO 711:1995.
3. Mix $300 \mathrm{mg}$ of milled soybean with $20 \mathrm{ml}$ of $0.1 \mathrm{M}$ buffer acetate, $\mathrm{pH} 5.6$ in a centrifuge tube.

4. Shake for $\mathbf{t}$ hours at $5^{\circ} \mathrm{C}$ in a thermostatized shaker, (t being the extraction time specified in the experimental design).

5. Centrifuge for 10 minutes at $5000 \times g$ with a refrigerated centrifuge.

6. Transfer $10 \mathrm{ml}$ of the supernatant to an erlenmeyer flask, add $0.1 \mathrm{ml} 0.1 \mathrm{M}$ calcium chloride solution, and $10 \mathrm{ml}$ of $0.5 \%$ soybean lecithin in ethyl ether solution.

7. Shake for $180 \mathrm{~min}$ at $5^{\circ} \mathrm{C}$ with a thermostatized shaker.

8. Add $1 \mathrm{ml}$ of $3 \mathrm{M}$ thrichloroacetic acid to stop the hydrolysis.

9. Eliminate the ethyl ether in a vacuum rotary evaporator.

10. Centrifuge for 10 minutes at $14000 \times \mathrm{g}$.

11. Go to step 1 of PLDA quantification according to Bergmeyer and Gavehn.

\subsection{Second extraction}

If a second extraction is to be performed on the same solids, remove and discard about $17 \mathrm{ml}$ of the supernatant from the centrifuge tube at the end of step 5, then add buffer acetate $0.1 \mathrm{M}, \mathrm{pH} 5.6$ to complete $20 \mathrm{ml}$ and repeat again from step 4 . (17 $\mathrm{ml}$ was the maximum volume that could be removed, according to the characteristics of the obtained precipitate).

\subsection{PLDA determined by the method without enzyme extraction (Tosi et al.,1999).}

1. Mill about $10 \mathrm{~g}$ of soybeans in a refrigerated mill up to ASTM \# 40 mesh.

2. Determine moisture content using about $4 \mathrm{~g}$ of milled soybean, according to ISO 711:1995.

3. Mix $150 \mathrm{mg}$ of milled soybean with $10 \mathrm{ml}$ of buffer acetate $0.1 \mathrm{M}$, pH 5.6; $0.1 \mathrm{ml} 0.1 \mathrm{M}$ calcium chloride solution, and $10 \mathrm{ml}$ of $0.5 \%$ soybean lecithin in ethyl ether solution in an erlenmeyer flask.

4. Continue as indicated in the extraction method starting from step 7 .

\subsection{PLDA quantification according to Bergmeyer and Gavehn}

1. Transfer $6 \mathrm{ml}$ of the supernatant to a $10 \mathrm{ml}$ centrifuge conical tube, add $1 \mathrm{ml}$ of $3 \%$ ammonium tetrathiocyanodiammonochromate (ammonium reineckate) in methanol solution and shake it with vortex. A light violet-pink color corresponding to the choline reinekate is observed.

2. Centrifuge for 5 minutes at $5000 \times g$.

3. Discard the supernatant, add $3 \mathrm{ml}$ of bidistilled water and shake it with vortex until 
the precipitate suspends. Centrifuge 10 minutes at $5000 \times \mathrm{g}$.

4. Repeat the washing as in step 3.

5. Discard the supernatant, add $3 \mathrm{ml}$ acetone and shake it with vortex until the precipitate is dissolved. (Warning: If there were small amounts of $\mathrm{Fe}$ or $\mathrm{Cu}$ present, a $\mathrm{Fe}$ or $\mathrm{Cu}$ reineckate complex acetone insoluble precipitate -characterized by a bluish colorwould be formed).

6. Centrifuge for 10 minutes at $5000 \times g$.

7. Measure the absorbance at $520 \mathrm{~nm}$ of supernatant against acetone blank.

8. Determine the amount of choline (mmoles) corresponding to the measured value of absorbance using a standard choline curve.

9. Calculation.

The PLDA is calculated by the expression:

where

$$
\text { PLDA }=K \frac{C}{(1-M)}
$$

$$
\mathrm{K}=\frac{\mathrm{L}}{\mathrm{V} \times \mathrm{G} \times \mathrm{t}_{\mathrm{e}}}
$$

PDLA Phospholipase D Activity (mmoles choline $\times$ gram of dry soybean $^{-1} \times \min ^{-1}$ )

C amount of choline in the choline reinekate precipitate (mmoles)

$\mathrm{V} \quad$ volume of aliquot of choline solution $(\mathrm{ml})$ (step 1 PLDA quantification method)

G mass of soybean flour (g) (step 3 in both methods)

M moisture content of soybean flour (wet basis) (g/g)

$\mathrm{L} \quad$ total volume of the aqueous phase $(\mathrm{ml})$

$t_{e}$ time of enzyme contact with the substratum ( $\mathrm{min})$

\subsection{Experimental design to optimize PLD extraction}

Tests were designed to determine the optimum extraction time $(\mathbf{t})$ and the number of extractions that maximize the PLD extraction from soybean flour, to compare both methods, and to determine if PLDA could be detected in solids remaining from the first extraction or in the liquid phase accompanying these solids.

All tests were carried out in triplicate; mean values and standard deviation were reported.

\section{Extraction time}

To evaluate the influence of the extraction time, triplicate tests for $1,2,3,4,5,6,8,10$ and 12 hours in step 4 of the extraction method were carried out.

\section{Number of extraction steps}

To establish the number of extractions needed to extract PLD from soybean flour; two successive extraction steps were carried out, both of them with an extraction time of 2 hours in step 4 . Briefly, an aliquot of the sample was submitted from steps 3 to 5 of the extraction method. Then $17 \mathrm{ml}$ of supernatant were discarded and buffer acetate 0.1 $\mathrm{M}, \mathrm{pH} 5.6$ was added to the remaining content up to $20 \mathrm{ml}$ total volume and back to step 4 .

\section{Remaining PLDA in the extracted solid}

As it was presumed of an incomplete extraction of PLD from the soybean matrix, the residual solid from step 5 of the extraction method was submitted to a PLDA determination according to the method without extraction.

\section{PLDA in the remaining supernatant}

Considering that the results from the previous determination on the remaining solids can be masked by the PLD present in the liquid phase which still remains with solids, another set of tests was carried out to measure PLDA in the residue from step 5 of the extraction method (after discarding the $17 \mathrm{ml}$ mentioned in previous step). To do so, buffer acetate $0.1 \mathrm{M}, \mathrm{pH} 5.6$ until $20 \mathrm{ml}$ of total volume was added to the residual solids from step 5 of the extraction method, and then continued as indicated in the extraction method starting from step 10.

\subsection{Standard choline curve}

To determine the amount of the obtained choline, an empiric relationship between the choline and the measured absorbance was used. Steps 1 to 11 of the extraction method were carried out, but specified amounts of choline standard solution ( $0.1432 \mathrm{mmoles}$ of choline per $\mathrm{ml}$ of solution) were added immediately after stopping the reaction with trichloracetic acid (step 8). Then steps 1 to 7 of Bergmeyer and Gavehn method were followed to measure the absorbance at $520 \mathrm{~nm}$.

Triplicate tests were carried out on five different amounts of choline solution, and a linear regression analysis was used to obtain the relationship that best fit the data set. Figure 1

\section{RESULTS AND DISCUSSION}

\subsection{Extraction method optimization}

Results in Table 1 show that PLDA reaches a maximum value of $3.2 \pm 0.43 \times 10^{-4}$ mmoles choline $\times \mathrm{g}_{\text {dry soybean }}{ }^{-1} \times \min ^{-1}$ at $2 \mathrm{~h}$ extraction time. With increasing extraction times a gradual decrease of the enzymatic activity was obtained, reaching a value of $0.9 \times 10^{-4}$ mmoles choline $\times$ $\mathrm{g}$ dry soybean ${ }^{-1} \times \min ^{-1}$ at $6 \mathrm{~h}$ or more extraction time. 


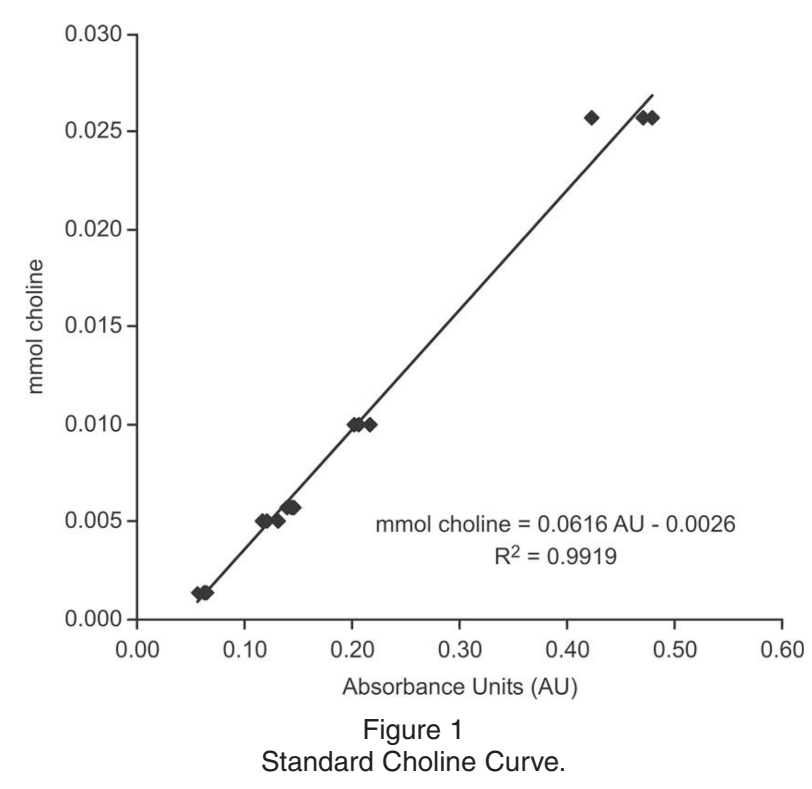

\subsection{PLDA in the extracted solids and in the remaining supernatant}

Results of the successive extractions, detailed in Table 2, show that PLDA of the samples submitted to a second extraction do not differ significantly from those corresponding to the dilution of the $3 \mathrm{ml}$ residual of the first extraction. Therefore, it seems that no PLD could be extracted with a subsequent extraction after the first one at the temperature, $\mathrm{pH}$, as well as quality and moisture content of soybeans used in this work. This may be attributed to a PLD linking in a lipidic-proteic matrix which makes its extraction impossible.

Table 1

Phospholipase $D$ activity as a function of extraction time (step 4 of extraction method) and without extraction.

\begin{tabular}{ccc}
\hline \multirow{2}{*}{$\begin{array}{c}\text { Extraction time } \\
{[\mathrm{h}]}\end{array}$} & $\begin{array}{c}\text { PLD activity } \times \mathbf{1 0}^{\mathbf{4}} \\
\text { [mmoles choline } \times \text { g dry } \\
\left.\text { soybean }^{-1} \times \text { min }^{-1}\right]\end{array}$ \\
\cline { 2 - 3 } & Average $^{\mathrm{a}}$ & $\begin{array}{c}\text { Standard } \\
\text { deviation }\end{array}$ \\
\hline 1 & 2.0 & 0.24 \\
2 & 3.2 & 0.43 \\
3 & 2.3 & 0.22 \\
4 & 1.7 & 0.08 \\
5 & 1.0 & 0.13 \\
6 & 0.9 & 0.06 \\
8 & 0.9 & 0.10 \\
10 & 0.9 & 0.14 \\
12 & 0.9 & 0.10 \\
\hline With extraction optimized & 3.2 & 0.43 \\
Without extraction & 6.1 & 0.65 \\
\hline
\end{tabular}

${ }^{a}$ From 3 replications
Table 2

Phospholipase D activity (PLDA) as a function of two successive extraction steps, for two $h$ extraction time and phospholipase $\mathrm{D}$ activity from the dilution of the remaining solution from step 5 of extraction method.

\begin{tabular}{ccc}
\hline & $\begin{array}{c}\text { PLDA } \times 10^{4} \\
{[\text { mmoles choline } \times \text { g dry }} \\
\text { soybean }^{-1} \times \text { min }^{-1} \text { ] }\end{array}$ \\
\cline { 2 - 3 } & Average $^{\text {a }}$ & $\begin{array}{c}\text { Standard } \\
\text { deviation }\end{array}$ \\
\hline $1^{\text {st }}$ extraction & 3.2 & 0.43 \\
$2^{\text {nd }}$ extraction & 1.7 & 0.22 \\
Dilution & 1.6 & 0.33 \\
\hline
\end{tabular}

${ }^{\text {a }}$ From 3 replications

\subsection{PLDA determined by the methods with and without extraction}

The values obtained by the two methods, that is, the optimized extraction method and the method without extraction were $3.2 \pm 0.43 \times 10^{-4}$ and 6.1 $\pm 0.65 \times 10^{-4}{\text { mmoles choline } \times \mathrm{g} \text { dry soybean }}^{-1}$ $\times \min ^{-1}$ respectively. Results obtained by the method that extracts the PLD previous to the activity determination are half of those obtained by the method which determines PLDA without extracting PLD from the soybean matrix.

PLDA values after the second extraction (1.7 \pm $0.22 \times 10^{-4}$ mmoles choline $\times \mathrm{g}$ dry soybean $^{-1} \times$ $\mathrm{min}^{-1}$ ) do not differ substantially from PLDA values measured in the remaining supernatant which moisten the solids after the centrifugation step 5 (dilution determination) $\left(1.6 \pm 0.33 \times 10^{-4}\right.$ mmoles choline $\times \mathrm{g}$ dry soybean ${ }^{-1} \times \mathrm{min}^{-1}$ ), PLDA is assumed to be modified by some alteration of PLD that occurs during the extraction steps.

In this work no studies were carried out to explain the mechanism which justifies such differences. A possible interpretation may be a partial denaturation of the extracted PLD due to the extraction medium. Such denaturation, which acts on topological characteristics of the active site, and consequently on the mechanism of the catalysis reaction, may interfere in the formation of intermediate phosphoenzime (Stuckey and Dixon, 1999) obstructing the choline release, the quantification of which was the basis of PLDA determination.

\section{CONCLUSIONS}

According to the obtained results the method including extraction is optimized by a single extraction, with an extraction time of two hours at $5^{\circ} \mathrm{C}$.

The PLDA values that result from the application of the method with enzyme extraction are lower than the ones obtained by means of the method without extraction. This is partly due to the fact that 
it is not possible to extract all the PLD contained in the soybeans and a fraction of it remains in the solid after the extraction.

The conditions of the medium in which PLD acts within the industry more closely resemble those where the method without enzyme extraction takes place than those originated by applying the method with enzyme extraction.

The method without enzyme extraction is simpler and demands less running time.

Bearing these results in mind, we consider the method without enzyme extraction a better choice for the determination of PLDA.

\section{REFERENCES}

Bergmeyer HU, Gavehn K. 1974. Methods of enzymatic analysis. 2nd Ed., Academic Press., New York, pp. 415-418.
List G, Mounts T, Lanser C, Holloway A. 1990. Effects of moisture, microwave heating and live steam treatment on phospholipase $\mathrm{D}$ activity in soybeans and soy flakes. JAOCS 67, 867-871.

List G, Mounts T, Lanser C. 1992. Factors promoting the formation of nonhydratable soybean phosphatides. JAOCS 69, 443-446.

Nakayama K, Saio K, Kito M. 1981. Decomposition of phospholipids in soybean during storage. Cereal Chem. 58, 260-264.

Stuckey J, Dixon J. 1999. Crystal structure of a phospholipase D family member. Nat. Struct. Mol. Biol. 8 (3), 278-284.

Tosi E, Cazzoli A, Ré E, Tapiz L. 1999. Soyben Drying in fluidized bed. Effect on the hydratable and nonhydratable phophatides. Concentration in crude and degummed crude oil. JAOCS 78 (10) ,1467-1470

Recibido: 4/8/06 Aceptado: 3/4/07 